Central Washington University

ScholarWorks@CWU

All Faculty Scholarship for the College of the Sciences

6-2-2017

Patterned Fluidity of Chinese Ethnic Identity: Networks, Time, and Place

Cynthia Baiqing Zhang

Follow this and additional works at: https://digitalcommons.cwu.edu/cotsfac

Part of the Chinese Studies Commons, and the Race and Ethnicity Commons 


\title{
Patterned Fluidity of Chinese Ethnic Identity: Networks, Time, and Place
}

\author{
Cynthia Baiqing Zhang'
}

\begin{abstract}
This study tests the salience/prominence of Chinese ethnic identity by applying identity theory, social identity theory, and social network analysis. Using survey data of Chinese graduate students in two universities in the United States, I show how Chinese ethnic identity salience varies with the percentage of Chinese in an individual's ego network revolving around him or her. In addition, among newcomers to the United States, as the percentage Chinese in ego networks increases, the decline of Chinese identity salience/prominence declines, but for old timers in the United States, as the percentage Chinese increases, the decline of Chinese identity salience/prominence is reversed. The ethnic identity salience lapses with time unless the respondents keep a cohort of co-nationals. Moreover, a cosmopolitan sociocultural environment is conducive to the maintenance of ethnic identity when an individual has many co-nationals in his or her ego network while having many conationals does not stop the decline of ethnic salience in an isolated social environment.
\end{abstract}

\section{Keywords}

Chinese ethnic identity, identity salience, ego network, location, time

\section{Introduction}

Structural symbolic interactionism emphasizes the impact of the structures of society on individuals' interaction with others to convey who they are, or the meanings of their identities. Self-consisting of multiple identities-emerges from the patterned and organized social structure and therefore is organized (Burke \& Stets, 2009). In contrast, traditional symbolic interactionism opposes any suggestion that social structure is stable and posits that identities are fluid as individuals construct identities differently across situations.

Along the lines of structural symbolic interactionism, identity theory specifically argues for the correspondence between social positions in networks of social relations and role identities such as student. Empirical work to test and explore the relationship between identity and network characteristics has appeared. McFarland and Pals (2005) operationalize ego network ${ }^{1}$ context such as prominence to predict identity change. Walker and Lynn (2013) suggest that role identity salience - the likelihood a role identity is enactedincreases as role-based others are more closely connected with non-role-based others. Stark (2015) reveals how the tendency to avoid friends who have minority friends enables majority group members to stay away from minority group members.

In this article, I answer this research question: Would Chinese respondents in the new environment of United States but with a large portion of Chinese acquaintances in their time network $^{2}$ develop a salient/prominent ethnic identity? Time network is composed of people with whom an individual spends the most awake time.

Further, this article aims to clarify whether being separated from the host culture of the United States reduces the salience/prominence of Chinese ethnic identity, or just among those who recently arrive in the host culture. Another aim of this article is to investigate whether low exposure to different cultures available in a locality reduces the salience/ prominence of Chinese ethnic identity, or just among those who have a large Chinese cohort.

\section{Theory and Hypotheses}

\section{Identity Prominence/Salience and Social Networks}

To reiterate, identity theory posits that social positions - the stable, morphological components of social structure - carry the shared behavior expectations termed "roles." Role identities exist as individuals participate in structured social relationships. Individuals are committed to role identities to various degrees, dependent on the costs of losing social relations that create behavioral expectations for roles. Such commitment can be measured qualitatively by emotional attachment to social

'Central Washington University, Ellensburg, WA, USA

\section{Corresponding Author:}

Cynthia Baiqing Zhang, Department of Sociology, Central Washington University, $400 \mathrm{E}$. University Way, Ellensburg, WA 98926, USA.

Email: Cynthiazhang7@gmail.com 
relations in support of certain roles, or "intensivity," and quantitatively by the number of social relations in support of certain roles, or "extensivity." Commitment is closely related with identity salience that predicts the likelihood of activation of certain identities organized in a salience hierarchy (Stryker, 1968). Given that networks of social relations are social structure (Wellman, 1988), the stable, morphological components of social structure as proposed by identity theory, or social positions, therefore, are social positions in social networks. Identity salience is a function of the strength and number of social relations in networks, or ties (Burke \& Stets, 2009). In short, Stryker and colleagues' work is particularly articulate on the relationship between identity salience and social networks.

\section{Social Identity Theory and Identity Theory}

Identity theory focuses on role identity that is related to role others. For example, a parent role is in relationship to a child role. Social identity such as Chinese ethnic identity emphsizes in-group (i.e. Chinese) and out-group (i.e. non-Chinese) differences. However, the argument on the relationship between identity salience and social networks as specified in identity theory can be extended to social identities. Phinny (Howard, 2000) has a comprehensive review of ethnic identity.

Identity theory scholars have actually called for a combination of identity theory and social identity theory (Stets \& Burke, 2000). Specifically, these scholars argue that the different bases of identity in social identity theory (category and group) and in identity theory (role) can be combined. Although category and group identity such as Chinese ethnic identity emphasizes the similarities among in-group members (Hogg, 2006) while role identity stresses differences between roles and counter roles such as student identity and professor identity, role identities can also be category and group identities as students and professors are in-group and out-group to each other. In addition, category, group, role, and person identities all follow the same identity verification mechanisms (Burke \& Stets, 2009).

\section{Chinese Ethnic Identity}

Chinese ethnic identity is a category identity. By definition, the Chinese ethnic identity is conditioned by the difference between Chinese and non-Chinese as well as by the similarities among Chinese as the in-group and similarities among non-Chinese as the out-group. Therefore, a social network measure that captures in-group out-group contrast - percentage of Chinese within the ego network - can be used to predict salience of Chinese ethnic identity.

In addition, because the in-group out-group contrast is key to category/group identity, the Chinese ethnic identity of a focal person - a Chinese person - is related with people the focal person spends much time with. In other words, to understand ethnic identity, it is necessary to know an individual's close relationships or ties that consist of the in-group as well as this person's acquaintances who are the out-group. Outgroup members are those who have constant presence in the focal person's life in geographical space but remain distant in social space. I thus use time network to delineate the relationship between identity salience/prominence and ego network characteristics.

\section{Hypotheses}

Social identity theory suggests that category identity is based on the distinction between in-group and out-group. For the in-group out-group distinction to maintain, there needs to be a balance between in-group members and out-group members in an individual's time network. Therefore, having a high percentage of Chinese in one's time network means the opportunity for a person to establish the distinction between Chinese and non-Chinese is low. I hereby hypothesize the following:

Hypothesis 1: Having many Chinese in the time network is negatively related with Chinese ethnic identity for Chinese egos.

Time is important because it takes time for identities to internalize. In this research, I am interested in short time spans: several months to approximately 8 years. That is, the time span that would have an impact on a stable, cross situational identity which is the focus of this project. I examine the impact of in-person and between-person time difference in the United States on network and identity formation and transformation.

In the literature of life course, Atchley (1993) suggests that time after retirement witnesses a U-shaped development of self-perception: honeymoon, disenchantment, reorientation, and stability. Changes in identities are constant while continuity in identities is more powerful. In addition, Burke maintains that identity salience decreases as individuals cannot verify their identities. With the passage of time, Chinese graduate students are more and more integrated into the host culture with more non-Chinese, the opportunity for these students to verify their Chinese identity becomes slimmer. However, this process can reverse as these students' life becomes stable. I hereby hypothesize the following:

Hypothesis 2: Time in the United States has a U-shaped relationship with Chinese identity.

Having a high Chinese composition in time network keeps individuals from being in contact with the host culture and thus reduces ethnic identity saliences. However, ethnic identity is fluid as individuals of various ethnic backgrounds are impacted by ecological factors, such as politics in their decision to claim or reclaim their ethnic identity (Alba, 1990; Nagel, 1994). With the passage of time, the decline of Chinese 
ethnic identity salience is slowed down as individuals are integrated more into the host culture. I hereby hypothesize the following:

Hypothesis 3: A longer stay in the United States will slow down the decline of Chinese identity salience when individuals have a higher Chinese cohort composition.

Sociocultural contexts or locations in the United States, another ecological factor influencing ethnic identity, are important in the interaction of identity and networks of social relations as this research is designed to test relational identity. Identity theory defines identity as internalized meanings existent in the culture in the larger society which is supported by ethnic identity literature (e.g., Ichiyama, McQuarrie, \& Ching, 1996). That is, identity meanings are culturally determined. Consequently, it is important to explain the "cultural contingency" of a social environment (Pachucki \& Breiger, 2010, p. 205). Social relations can be the precedence or the consequence of identities depending on the specific social environments. A social environment provides the cultural meanings that may be absorbed into the self-structure, and thus constrains the types of available identities. More complex social environments can potentially generate more identities because of the many subcultures existent in such environments. Social environments also offer different types of social relations at the dyadic and group levels which either enhance or constrain the formation of new identities.

In addition, distinctiveness theory (Mehra, Kilduff, \& Brass, 1998) proposes that in a given situation, the trait such as race that is the rarest in the crowd will draw people with that trait together. Therefore, in an environment where ethnic background is the rarest trait, people feel more strongly about their ethnic identity. However, in a social context where diverse ethnic groups are present, people feel less strongly about their ethnic identity. I hereby hypothesize the following:

Hypothesis 4: Being in Northeast City (NE) in the New England area with exposure to various cultures is negatively related to Chinese identity compared with residents from Southeast City (SE).

As stated previously, having a high percentage Chinese in one's network has a negative relationship with identity salience/prominence. However, being in NE stems the decline of Chinese ethnic identity salience/prominence because the existence of multiple cultures renders Chinese ethnic background a sharp contrast to the host culture in the United States. As explained by Howard (2000), "Population shifts, especially immigrations, are a major instigator of changes in ethnic identities" (p. 375). I hereby hypothesize the following:
Hypothesis 5: Being in NE slows down the decline of Chinese ethnic identity salience at a higher Chinese composition.

\section{Method}

\section{Sample and Procedure}

To identify patterns of linkages between ego network, time in the United States, and localities in the United States and identity, I conducted online surveys (Sue \& Ritter, 2007) with a supplementary paper version of the surveys (Dillman, 2007; Weiseburg, 2005) targeting the entire population of Chinese graduate students at two universities. I used two public universities-Harmony College in SE and Diversity College in $\mathrm{NE}$ as the subject frames though the subject's ego network usually reached far beyond the boundaries of the two colleges, extending to the local communities and to their home country of China, assisted by physical and electronic interaction, particularly when these students first arrived in the United States and in their interaction with their family members back in China. Because the students from the two universities were similar in terms of educational attainment in China, localities in China, age group, and being city residents in China, I did not include variables associated with their Chinese background to predict identity salience/prominence.

The survey was distributed to all Chinese graduate students through university administrative offices. Although I did not know the exact number of the Chinese graduate students at Diversity College, I estimated the combined responses for the online version of the survey from the two universities probably accounted for around $15 \%$ of the population. The print version fared much better. The two batches of mail survey using exactly the same online format witnessed $70 \%$ response rate. Some responses in the second batch were not included because they arrived later than the deadline. There were 95 total responses to the online survey at Harmony College. At Diversity College, there were 21 responses to the online survey and 56 responses to the print version of the online survey. In total, Diversity College provided 77 responses to the survey. Usable responses were 119 from the two colleges which was sufficient for a multivariate analysis (Allison, 1999).

The survey asked for the respondents' general sociodemographic information, respondents' time network, and the importance of ethnic identity. For each person named in time network, I asked about his or her demographics and relationships with the focal person. I also asked for an aggregate number of ties in time network. I calculated percentage of Chinese for the networks thus obtained in the survey.

The identity salience/prominence section asked the respondent to rate the importance of ethnic identity (Chinese from mainland China). The question read, "We now ask the importance of the major identities you might have. Please drag the importance indicator along the scale $0-100$, ' 1 ' being least important and ' 100 ' the most important." 
Table I. Demographic and Cultural Diversity Comparison of the SE and NE against the United States as a Country.

\begin{tabular}{lccc}
\hline Demographics & Southeast city & Northeast city & United States \\
\hline Population & $5 \%$ & $100 \%$ & \\
White & $75.70 \%$ (non-Hispanic $73.00 \%)$ & $44.00 \%$ (non-Hispanic $33.30 \%)$ & $77.90 \%($ non-Hispanic $63.00 \%)$ \\
African American & $14.50 \%$ & $25.50 \%$ & $13.10 \%$ \\
Native American & $0.30 \%$ & $0.70 \%$ & $1.20 \%$ \\
Asian & $3.20 \%$ & $12.70 \%$ & $5.10 \%$ \\
Hispanic or Latino & $6.90 \%$ & $28.60 \%$ & $16.90 \%$ \\
Other races & $2.50 \%$ & $4.00 \%$ & $2.40 \%$ \\
Foreign born & $8.50 \%$ & $36.80 \%$ & $12.80 \%$ \\
Language other than English spoken & $11.10 \%$ & $48.50 \%$ & $20.30 \%$ \\
$\quad$ at home & $39.30 \%$ & $33.70 \%$ & $28.20 \%$ \\
Education (BA or higher) & 29,125 & 31,417 & 27,915 \\
Per capita money income & $17.90 \%$ & $19.40 \%$ & $14.30 \%$ \\
Income (\% in poverty) & & & \\
\hline
\end{tabular}

Source. U.S. Census Bureau (2010).

The survey took approximately 10 to 15 min to complete on average though some respondents took longer (20-25 $\mathrm{min}$ ). Students read a verbal script highlighting the voluntary nature of the questionnaire and my intent of protecting their anonymity.

For the analysis, I used both the basic term and the quadratic term of the time in the U.S. variable. First, I used percentage Chinese, time, a quadratic term of time, and locations as predictors and network size as control variable. Second, I added interaction terms of the basic term and the quadratic term of time, with the two network measures: percentage Chinese and network size. Third, I added the interaction terms of location in the United States with the two network measures. I also added another control variable of gender with male coded as 1 .

\section{Measures}

The dependent variable identity salience/prominence was measured using a scale of identity importance ranging from 1 to 100 . McCall and Simmons (1966) regard self-attributed importance of identities as the fundamental elements of self. Although defining identity salience as behavioral oriented, Stryker and colleagues use identity salience and identity prominence interchangeably as a concept and measure (Stryker \& Serpe, 1994).

Time in the United States was measured with years the respondents had spent in the host country. Because the vast majority of the respondents started their graduate program immediately upon arrival in the host country of the United States, I recoded time in graduate programs as time in the United States. As a new identity for the respondents, Chinese ethnic identity showed a trajectory in salience/prominence with the passage of time. This identity change process is gradual and takes place over a long period of time, ranging from weeks to months or even years (Burke \& Stets, 2009).
Location in the United States was measured by delegating "1" to NE and "0" to Southeast city. These two locations were selected because they demonstrated tremendous differences in ethnic compositions and degrees of cultural diversity as shown in Table 1.

\section{Major Predictor: Percentage Chinese in Ego's Time Network}

The major network measure to predict identity salience/ prominence was percentage Chinese. The percentage Chinese measure was calculated by dividing the number of Chinese ties within a person's time network by the person's total number of ties. Percentage Chinese indicates a focal person's access (Burt, 1984) to in-group members (Chinese) and by definition nonaccess to out-group members (non-Chinese). Descriptive analysis and hypotheses testing were based on these data using Stata. The larger the percentage Chinese measure is, the larger the Chinese in-group is for the individual. Stated in a different way, larger percentage Chinese measure shows that an individual was more embedded in his or her home Chinese culture. Or conversely, larger percentage Chinese measure means that an individual was having limited contact with the host culture.

\section{Control Variables: Network Size and Gender}

I included two control variables: the size of the time network and gender. Identity theory maintains that the number of ties supporting an identity is important to predict identity salience/prominence (Burke \& Stets, 2009; Stryker \& Serpe, 1994). Chinese and non-Chinese both functioned to help a focal person to maintain the Chinese ethnic identity as defined by the concept of ethnic identity. Chinese cohorts reminded an individual of what Chinese culture specified while non-Chinese acquaintances were a contrast group. 
Table 2. Sample Descriptive Statistics $(N=119)$.

\begin{tabular}{lrrc}
\hline & $M$ & SD & Range \\
\hline Gender (male = I) & 0.50 & & \\
Age (years) & 27.05 & 3.56 & $20.00-38.00$ \\
Location (NE = I) & 0.54 & & \\
Time in the United States (years) & 3.20 & 2.04 & $0.00-9.00$ \\
Time network size & 3.90 & 3.24 & $0-20$ \\
\% Chinese in time network & 83.06 & 28.45 & $0-100$ \\
\hline
\end{tabular}

Table 3. Results of Regression Analysis.

\begin{tabular}{|c|c|}
\hline Dependent variable & $\begin{array}{c}\text { Identity salience/ } \\
\text { prominence }\end{array}$ \\
\hline \multicolumn{2}{|l|}{ Control variables } \\
\hline Time network size & 1.10 \\
\hline Gender & 5.14 \\
\hline \multicolumn{2}{|l|}{ Main effects } \\
\hline \% Chinese & $-0.66^{*}$ \\
\hline USYRs & $-14.93 *$ \\
\hline USYRs ${ }^{2}$ & 0.61 \\
\hline Location in the United States (NE) & $-50.82 *$ \\
\hline \multicolumn{2}{|l|}{ Interaction } \\
\hline$\%$ Chinese $\times$ Time in the United States & $0.13 * *$ \\
\hline $\begin{array}{l}\% \text { Chinese } \times \text { Location in the United } \\
\text { States }(N E)\end{array}$ & $0.56^{*}$ \\
\hline $\mathrm{F}$ & $2.78 *$ \\
\hline Overall $\mathrm{R}^{2}$ & .20 \\
\hline Adjusted $\mathrm{R}^{2}$ & .13 \\
\hline
\end{tabular}

Note. Two-tailed hypothesis test; USYRs, time in the United States. $* p<.05$. **p $<.01$.

Gender was included as a control variable because literature suggests people experience the host culture in the United States differently as a result of their gender, particularly immigrants from Asian countries (Kim, 2006; Pyke \& Johnson, 2003).

\section{Results}

The demographic characteristics of the survey respondents are presented in Table 2 .

Around half of the sample was male (50\%). Respondents ranged in age from 20 to 38 years with a mean age of 27 years. Over half of the sample was from Diversity College $(54 \%)$. The length of stay in the United States ranged from 0 to 9 years, with a mean of 3.2 years.

There were two network variables included in the descriptive statistics. The time network size was 3.90 on average with a $S D$ of 3.24. The number of ties ranged from 0 to 20 . The percentage of Chinese people in this network was high: $83.06 \%$ with a $S D$ of $28.45 \%$.

Results of regression analysis are presented in Table 3.

As shown in Table 3, Hypotheses 1, 3, 4, and 5 were supported. Consistent with social identity theory, having many

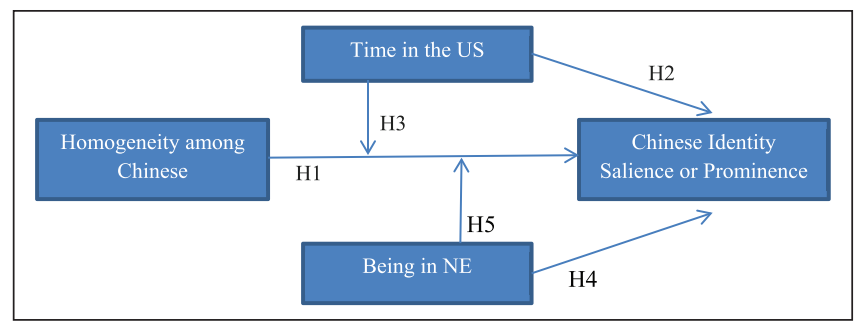

Figure I. Full model using hypotheses.

Chinese co-nationals in one's time network deprived a person's opportunity to perceive the boundary between Chinese and nonChinese due to the lack of separation from the native Chinese culture. Hypothesis 1 was supported that the higher percentage of Chinese cohorts an individual had, the lower his or her Chinese ethnic identity salience/prominence $(\beta=-.66, p<.05)$ was.

Contrary to the literature on the relationship between time and identity in general, results showed no significant U-shaped relationship between the time spent in the United States and Chinese ethnic identity. Therefore, Hypothesis 2 was not supported. However, there was a significant negative relationship between time spent in the United States and Chinese ethnic identity $(\beta=-14.93, p<.05)$. That is, Chinese ethnic identity was the strongest when the respondents first arrived in the United States and diminished as they were more and more integrated into the host culture in the United States. This can be because China is a highly homogeneous country with over $90 \%$ of the population belonging to the Han ethnic group while the host country of the United States has a very small percentage Chinese in its population. This conclusion is not surprising as the literature on the relationship between time and ethnic identity does support that the length of time in a new environment and the identification with home culture have a negative relationship (Ichiyama et al., 1996).

The analysis also revealed a negative relationship between being in NE and Chinese ethnic identity $(\beta=-50.82, p<$ $.05)$. That is, being a resident of NE which is highly diverse in racial composition and cultures led to lower Chinese ethnic identity. Therefore, Hypothesis 3 is supported.

Hypotheses 4 and 5 predicted moderation effects of time and place in the relationship between percentage Chinese and identity salience/prominence. There was a significant interaction between percentage Chinese and time in the United States $(\beta=0.13, p<.01)$. There was also a significant interaction between percentage Chinese and place $(\beta=0.56$, $p<.05$ ). Figures 1 and 2 showed the moderation effects of time and place, respectively, on the relationship between identity salience/prominence and percentage Chinese.

As shown in Figure 2, the negative relationship between identity salience/prominence and percentage Chinese was significantly strengthened among residents of SE while only marginally lowered among residents of NE. These findings have been confirmed by the slope analysis (Aiken \& West, 1991). For residents in NE, the simple slope for the first-order $t$ was Y 


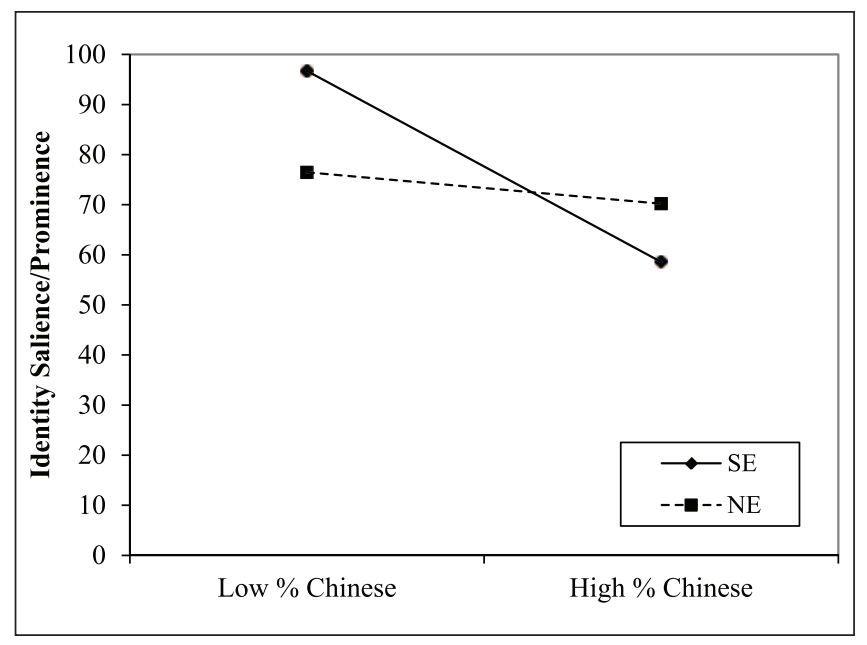

Figure 2. Moderation effect of location on identity salience/ prominence at lower and higher percentage Chinese.

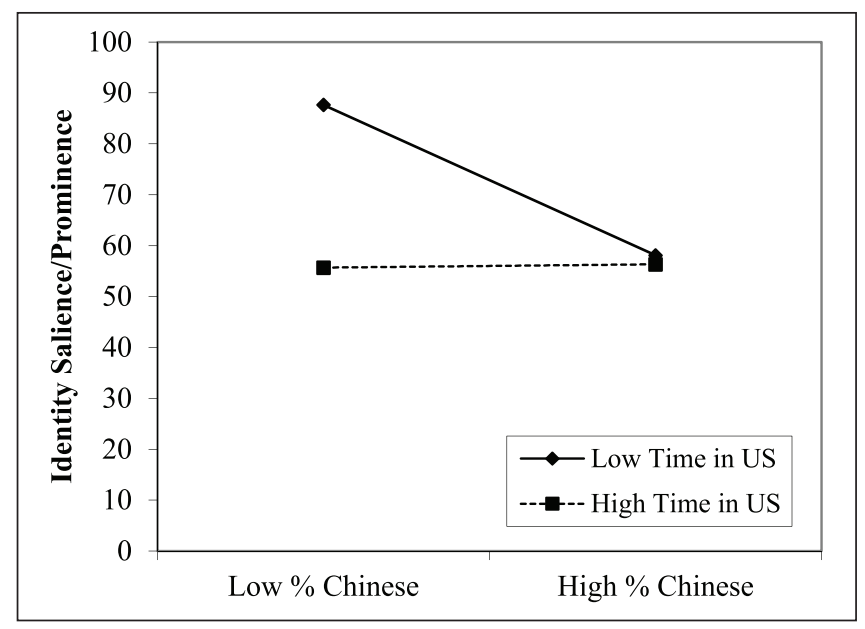

Figure 3. Moderation effect of time in the United States on Chinese ethnic identity salience/prominence at lower percentage Chinese and higher percentage Chinese.

$=(-0.1) \mathrm{X}+82.18(t=3.08, p<.01)$. For residents in $\mathrm{SE}$, the simple slope for the first-order $t$ was $\mathrm{Y}=(-0.66) \mathrm{X}+133(t=$ $-0.98, p<.34)$. That is, among residents in NE, as the percentage Chinese increased in ego networks, the decline of Chinese identity salience/prominence also declined but at much a lower rate compared with residents in SE.

For respondents from NE, the average score of Chinese ethnic identity was 73.88. For respondents from SE, the average score of Chinese ethnic identity was 78.18.

As Figure 3 illustrates, the negative relationship between identity salience/prominence and percentage Chinese was significantly strengthened among residents who had stayed in the United States for a short period of time while marginally reversed among respondents who had stayed in the United States for a longer period of time. These findings have been confirmed by the slope analysis (Aiken \& West, 1991). For respondents with a short stay of 1.16 years in the United States on average, the simple slope for the first-order $t$ was $\mathrm{Y}=(-0.52)$ $\mathrm{X}+116(t=-0.7, p<.49)$, and the average score of Chinese identity salience/prominence was 72.81 . For respondents with a stay of 5.24 years in the United States on average, the simple slope for the first-order $t$ was $\mathrm{Y}=(0.01) \mathrm{X}+55.07(t=2.82, p<$ .01 ), and the average score of Chinese identity salience/prominence was 55.9. In other words, among newcomers to the United States, as the percentage Chinese increased in ego networks, the decline of Chinese identity salience/prominence declined, but for old timers in the United States, as the percentage Chinese increased in ego networks, the decline of Chinese identity salience/prominence was reversed.

\section{Discussion}

\section{Implications}

This study contributes to our understanding of the social contexts in which ethnic identity varies in salience/prominence. The immediate social environment of ego network provides the arena for the cognitive and affective formation of ethnic in-group and out-group contrast for a person. However, ego network is not immune to the larger social context with various ethnic compositions in population and different degrees of culture diversity. A cosmopolitan sociocultural environment with high degree of diversity in terms of race/ethnicity and culture is conducive to the maintenance of ethnic identity when an individual has many co-nationals in his or her ego network. On the contrary, having many co-nationals in one's ego network does not stop the decline of ethnic salience/prominence in an isolated social environment.

Also, as an ethnic group who are recent arrivals in the United States from a highly homogeneous social context in mainland China, the heightened sense of ethnic identity formed at arrival lapses with time as the respondents become more familiar with the social environment in the United States. However, keeping a cohort of co-nationals changes the function of time on Chinese ethnic identity salience. Among newcomers to the United States, as the percentage Chinese increases in ego networks, the decline of Chinese identity salience/prominence declines, but for old timers in the United States, as the percentage Chinese increases in ego networks, the decline of Chinese identity salience/prominence is reversed. Ethnic identity seems to require a balance between host culture and home culture to maintain.

The reason for the function of the percentage Chinese to vary with time can be the different degree of consciousness about the differences between their home culture and the host culture. As the newcomers have limited knowledge of the host culture in the United States, by keeping many co-nationals in their social networks, they construct a home culture around them and thus do not have to confront the differences between their home culture and the host culture. Without knowledge of the differences between their home culture and host culture, their ethnic identity gradually declines in salience. However, 
for old timers, knowledge of the host culture is much more profound. Thus, when they also have many co-nationals in their social networks, the differences between their home culture and host culture maintain sharp in their consciousness as a result of deepened knowledge of the host culture and familiarity with the home culture. This mindset is conducive to high ethnic identity salience.

This study highlights the importance of the assumption of structural symbolic interactionism: the stability of social structure exemplified in social positions in social networks and corresponding identities. In addition, the wisdom of identity theory that social structure is multi-layered (Merolla, Serpe, Stryker, \& Schultz, 2012) is confirmed by the impact of locality on the interaction of ego networks and identity salience/ prominence. This wisdom is reiterated by scholars in social network analysis as the ecological perspective of social networks (McFarland, Moody, Diehl, Smith, \& Thomas, 2014). Last but not least, the verification model proposed by Burke and colleagues (Burke \& Stets, 2009) seems to be a robust model as ethnic identity salience/prominence declines when an individual living in an isolated social environment with many other co-nationals cannot verify his or her ethnic identity based on in-group out-group distinction because this person never separates from his or her native culture. Meanwhile, the fluidity of ethnic identity is highlighted with the significant impact of time and location on the interaction of identity salience/prominence and ego networks. Therefore, the variance of ethnic identity can be described as patterned fluidity.

\section{Limitations of Study}

I use identity prominence to measure identity salience. A better measure of identity salience needs to replace the current identity importance measure as identity salience is behavior oriented while identity importance has various conceptualizations. Identity prominence and salience were merged conceptually and empirically in earlier works (Stryker \& Serpe, 1994). In addition, a distinction and a causal ordering between identity prominence and salience have been made, tested, and supported (Brenner, Serpe, \& Stryker, 2014). However, because ethnic identity is a valued identity, the results should remain the same using a behavior-oriented measure given the causal relationship between identity prominence and salience.

The dependent variable of identity prominence is measured by one-item question of how important Chinese ethnic identity is. Although one-item measure of identity prominence was used by scholars researching on identity, multipleitem measure of identity salience provides better reliability and has been proposed by Stryker and colleagues (Merolla et al., 2012). Future studies should use the multi-item measure of identity salience.

The calculation of the major predictor percentage Chinese is based on respondents' estimates of the number of total ties and Chinese ties in their time network. The advantage of calculating percentage Chinese using estimates is that respondents are not limited to a certain number of ties. However, because of cognitive obstacles respondents experience when recalling people in their time network, such a measure suffers in precision compared with ties generated through a name generator. Future research can use name generator for better measure of percentage Chinese.

\section{Future Researches}

Limitations notwithstanding, the article presents some important findings and has important implications. The immediate social environment of ego networks is a significant predictor of identity salience. The ecological factors of place and time add complexity to the relationship between ego networks and identity salience. We must be conscious of the balance between the stability and fluidity of the Chinese ethnic identity conditioned by various levels of social structure.

This study relates to the gradual growth of the scholarship on the link between identity and social networks as follows. First, this research on Chinese ethnic identity and social networks is a continuation of the current literature with its emphasis on using network measures highlighting the structure of social networks to predict identity variables. Walker and Lynn (2013) find that the "embeddedness of RBOs, the breadth of access that a role-based group has to the rest of an individual's network" is statistically significant to predict the salience of religious, student, and work identities (p. 151). McFarland and Pals (2005) suggest network measures of prominence, homogeneity, and bridging are more powerful in predicting identity change than categories. Stark (2015) proposes that the "triadic closure" mediates the effect of prejudiced individuals' avoidance of friendships with members of minority groups. Similarly, in this study, the measure of proportion of Chinese in a Chinese graduate student's network is a structural measure of an individual's network: these students' access to co-nationals, or their nonaccess to the host culture in the United States.

Second, this study differs from the current identity theory literature in the measure of identity salience. Brenner, Serpe, and Stryker (2014) use a more behavior-oriented definition for identity salience in recent works and show a causal relationship between identity salience and identity prominence. This study uses an importance indicator to measure identity salience. However, as there is a causal relationship between identity salience and identity prominence and ethnic identity is a valued identity similar to other valued identities, it is highly likely a more behavior-oriented measure of identity salience as used by Stryker and colleagues would yield similar results as the one used in this study with regard to the link between identity salience and social networks.

Third, this study adds to the literature on the link between identity and social networks by analyzing a social identity: Chinese ethnic identity. Previous researches investigate how network structure impacts role identities, which are the focus of identity theory. This article shows that the salience of social identities can also be predicted by network measures. The combination of identity theory and social identity theory 
substantiated by social network analysis provides new theoretical insight into the identity processes.

That is, researchers can examine other social identities such as nationality based identities and gender identity with a nationality or gender homogeneity measure because the ethnic homogeneity network measure - proportion of Chinese in a focal person's network - is effectively used for the analysis of Chinese ethnic identity in this study. Essentially, category/ group identities are grounded in the contrast between the ingroup and the out-group. Therefore, the proportion of people with the same category/group membership is a feasible measure for access to people with the same category/group membership. This is an addition to the current literature and explains why the homogeneity measure is not a functional measure for role identities such as student as found by Walker and Lynn (2013).

\section{Acknowledgments}

Among the many people in the writing of this article, author would like to particularly thank Professors Yu-ping Liu-Thompkins, James Hougland, and Daniel S. Halgin.

\section{Declaration of Conflicting Interests}

The author(s) declared no potential conflicts of interest with respect to the research, authorship, and/or publication of this article.

\section{Funding}

The author(s) received no financial support for the research, authorship, and/or publication of this article.

\section{Notes}

1. A network revolving around a focal person.

2. I also collected data of people who are emotionally important to an individual and who discuss important issues with the focal person. Such network data do not explain ethnic identity, though.

\section{References}

Aiken, L. S., \& West, S. G.. (1991). Multiple regression: Testing and interpreting interactions. Newbury Park, London, and New Dehli: Sage Publications.

Alba, R. D. (1990). Ethnic identity: The transformation of White America. Binghamton, NY: Vail-Ballou Press.

Allison, P. D. (1999). Multiple regression: A primer. Thousand Oaks, CA: Pine Forge Press.

Atchley, R. C. (1993). Continuity theory and the evolution of activity in later adulthood. In J. R. Kelly (Ed.), Activity and aging: Staying involved in later life (pp. 1-5). Newbury Park, CA: Sage.

Brenner, P. S., Serpe, R. T., \& Stryker, S. (2014). The causal ordering of prominence and salience in identity theory: An empirical examination. Social Psychology Quarterly, 77, 231-252.

Burke, P. J., \& Stets, J. E. (2009). Identity theory. Oxford, UK: Oxford University Press.

Burt, R. S. (1984). Network items and general social survey. Social Networks, 6, 293-339.

Dillman, D. A. (2007). Mail and internet surveys: The tailored design method. Hoboken, NJ: John Wiley.
Hogg, M. A. (2006). Social identity theory. In P. J. Burke (Ed.), Contemporary social psychological theories (pp. 111-136). Stanford, CA: Stanford University.

Howard, J. A. (2000). Social psychology of identity. Annual Review of Psychology, 26, 367-393.

Ichiyama, M. A., McQuarrie, E. F., \& Ching, K. L. (1996). Contextual influences on ethnic identity among Hawaiian students in the mainland United States. Journal of Cross-Culture Psychology, 27, 458-475.

Kim, N. Y. (2006). "Patriarchy is so third world": Korean immigrant women and "migrating" white western masculinity. Social Problems, 53, 519-536.

McCall, G. J., \& Simmons, J. L. (1966). Identities and interactions. New York, NY: The Free Press.

McFarland, D., Moody, J., Diehl, D., Smith, J. A., \& Thomas, R. (2014). Network ecology and adolescent social structure. American Sociological Review, 79, 1088-1121.

McFarland, D., \& Pals, H. (2005). Motives and contexts of identity change: A case for network effects. Social Psychology Quarterly, 68, 289-315.

Mehra, A., Kilduff, M., \& Brass, D. (1998). At the margins: A distinctiveness approach to the social identity and social networks of underrepresented groups. Academy of Management Journal, 41, 441-452.

Merolla, D. M., Serpe, R. T., Stryker, S., \& Schultz, P. W. (2012). Structural precursors to identity processes: The role of proximate social structures. Social Psychology Quarterly, 75, 149-172.

Nagel, J. (1994). Constructing ethnicity: Creating and recreating ethnic identity and culture. Social Problems, 41, 152-176.

Pachucki, M. A., \& Breiger, R. L. (2010). Cultural holes: Beyond relationality in social networks and culture. Annual Review of Sociology, 36, 205-224.

Pyke, K. D., \& Johnson, D. L. (2003). Asian American women and racialized femininities. Gender \& Society, 17, 33-53.

Stark, T. H. (2015). Understanding the selection bias: Social network processes and the effect of prejudice on the avoidance of outgroup friends. Social Psychology Quarterly, 78, 127-150.

Stets, J. E., \& Burke, P. J. (2000). Identity theory and social identity theory. Social Psychology Quarterly, 63, 224-237.

Stryker, S. (1968). Identity theory and role performance: The relevance of symbolic interaction theory for family research. Journal of Marriage and Family, 30, 558-564.

Stryker, S., \& Serpe, R. T. (1994). Identity salience and psychological centrality: Equivalent, overlapping, or complementary concepts? Social Psychology Quarterly, 57, 16-35.

Sue, V. M., \& Ritter, L. A. (2007). Conducting online surveys. Los Angeles, CA: Sage.

Walker, M. H., \& Lynn, F. B. (2013). The embedded self: A social networks approach to identity theory. Social Psychology Quarterly, 76, 151-179.

Weisburg, H. F. (2005). The total survey error approach: A guide to the new science of survey research. Chicago, IL: The University of Chicago Press.

Wellman, B. (1988). Social structures: A network approach. Cambridge, MA: Cambridge University Press.

\section{Author Biography}

Cynthia Baiqing Zhang is an assistant professor with the Department of Sociology at Central Washington University. Her research areas include identity, race/ethnicity, crime/deviance, organizational studies, and social network analysis. 